\title{
Gender Heterogeneity in the Effect of Telework on Labor Market Outcomes during the COVID-19 Pandemic
}

\author{
Jingbo Hou \\ Arizona State University \\ jhou27@asu.edu \\ Pei-yu Chen \\ Arizona State University \\ peiyu.chen@asu.edu
}

\author{
Chen Liang \\ University of Connecticut \\ chenliang@uconn.edu \\ Bin $\mathrm{Gu}$ \\ Boston University \\ bgu@bu.edu
}

\begin{abstract}
With the massive COVID-19 lockdown, teleworkability, i.e., the feasibility of telework, plays an important role in determining whether workers can maintain productivity and keep their jobs. However, the impact of teleworkability is likely to be heterogeneous, varying by worker characteristics, such as gender and childcare constraints. This study examines the heterogeneous impact of teleworkability on labor market outcomes (including unemployment, work absence, and layoff). Using stay-at-home order as a measure of labor market disruption, we find that teleworkability offsets the increase in unemployment due to the disruption of COVID-19 by 20\%, that in work absence by $28 \%$, and that in layoff by $26 \%$. Specifically, the positive effect of teleworkability is i) stronger for females than males; ii) stronger for females with kids than their male counterparts as well as those without kids. Our study contributes to the emerging literature on gender inequality by underscoring the nuanced impact of teleworkability.
\end{abstract}

\section{Introduction}

COVID-19 has significantly changed the way people live and work. Since the unexpected outbreak of COVID-19 in March 2020, millions of Americans had been asked by their states and/or counties to do what would have been unthinkable before: don't go to the workplace, don't go to school, don't leave the house, unless they have to. While the stay-at-home order was able to slow down the spread of COVID-19 by ordering most residents to stay at home except for

\footnotetext{
${ }^{1}$ https://www.bls.gov/news.release/empsit.nr0.htm

${ }^{2}$ https://time.com/5876604/machines-jobs-coronavirus/

${ }^{3}$ https://www.npr.org/2020/10/28/928253674/stuck-at-homemoms-the-pandemics-devastating-toll-on-women
}

certain essential activities, it had strong negative impacts on the labor market since millions of people were unable to perform their work at the workplace.

Due to the restriction on social gatherings and the enforced closure of nonessential businesses, the COVID-19 pandemic has ravaged national economies with massive job losses and school (as well as daycare) closures. According to the Labor Department, 3.6 million workers had been unemployed for 27 weeks or more (i.e., long-term unemployed) in October $2020^{1}$ and many job losses were likely permanent. ${ }^{2}$ Moreover, there is growing academic and anecdotal evidence that the COVID-19 pandemic has disproportionately harmed females' employment due to the increased childcare demands (e.g., [1-2]), suggesting a larger gender employment gap. For example, in September 2020, as many as 865,000 females left the workforce--four times more than males. $^{3}$

To adapt to the workplace disruption from the COVID-19 pandemic and the stay-at-home order, an unprecedented number of companies had to send their employees home to work remotely. Based on the May 2020 Current Population Survey (CPS), about 35\% of employed persons teleworked or worked from home for pay because of the COVID-19 disruption. Here, telework (or teleworking) refers to a work flexibility arrangement under which an employee performs the duties and responsibilities of such employee's position, and other authorized activities, from an approved worksite other than the location from which the employee would otherwise work. ${ }^{4}$ While avoiding virus transmission in the workplace or their commute to work, telework can help workers keep their jobs

\footnotetext{
${ }^{4}$ https://www.opm.gov/FAQs/QA.aspx?fid=b48bf83b-440c-4f1ea88c-3cdc9d802ac8\&pid=75346675-3b92-4aec-831d-
} $58 \mathrm{cf} 5 \mathrm{~b} 0 \mathrm{e} 86 \mathrm{~d} 2$ 
during the stay-at-home order. However, notably, not all job duties can be performed at home. It's found that only $37 \%$ of jobs in the United States can be performed entirely at home, with significant variations across occupations [3]. In this regard, teleworkability, the feasibility of workers in a specific occupation that can telework, is crucial to workers' fight against the widespread pandemic-induced job losses.

Despite the (presumed) general positive effect of telework on labor market outcomes (e.g., unemployment, absence, lay off), the evidence is rather mixed as to whether and to what extent telework can benefit females more than males and thus help to narrow the gender employment gap during the pandemic. On the one hand, telework has long held an appeal for female workers because it can bring more flexibility to them (e.g., [4-5]) and thus ease the workfamily conflict. In particular, females tend to have a higher need for flexibility [6] to alleviate the workfamily conflict during the pandemic, suggesting that telework is likely to be more critical and beneficial to females than males. From this perspective, the flexibility from telework is likely to empower females more than males by helping them achieve work-life balance, which subsequently reduces work absence or unemployment due to family responsibilities [7].

On the other hand, increasing anecdotal evidence indicates the increasing gender inequality in telework during the pandemic due to the higher burden of household chores and childcare on females. According to a survey from Boston Consulting Group, on average, women in the labor force spent 15 hours per week more on unpaid domestic work than their male counterparts. ${ }^{5}$ The unequal burden of unpaid domestic work during the pandemic as the result of the closure of schools and daycare facilities may put females in a disadvantaged position. Accordingly, females may find themselves having to sacrifice work for their families or constantly being distracted due to working with kids around [8]. In other words, the unequal burden of unpaid domestic work may crowd out the job opportunities provided by telework for females, suggesting that telework may play a less beneficial role in females' labor market outcomes due to childcare constraints. To sum up, two competing effects are contributing to the gender heterogeneity of telework. Whether telework can widen or narrow the gender employment gap during the pandemic is an open question that deserves further investigation.

To fill this gap, we examine the gender heterogeneous impact of telework on workers' labor market outcomes during the COVID-19 pandemic in terms of the unemployment rate, work absence rate, and layoff rate. Specifically, we are interested in the following research questions:

1) Does telework have a positive effect on the labor market outcomes of workers during the COVID19 disaster?

2) If so, do females benefit more or less from telework compared to their male counterparts?

3) How do childcare constraints play a role in the potential gender heterogeneous effect of telework?

\section{Related Studies and Hypotheses Development}

\subsection{The Effects of Telework on Workers' Labor Market Outcomes}

During the stay-at-home order, non-essential businesses are either closed temporarily or adapted to having employees working from home. In this regard, telework can help to ensure workers' productivity during catastrophic events and thus improve their labor market outcomes.

For teleworkable jobs, workers usually still have comparable or even higher productivity when working from home during the pandemic than when working in workplaces [9], such as office clerks. By comparison, for non-teleworkable jobs, such as restaurant workers, firms are at high risk of future shutdowns. Those unpredictable interruptions in production and the challenge of the slow recovery are likely to negatively affect workers' productivity and their labor market outcomes. Specifically, workers' labor market outcome can be measured with the following variables: i) unemployed, i.e., whether workers are currently unemployed, ii) work absent, i.e., whether they have just been absent from work recently, and iii) laid off, i.e., whether they have just been laid off recently. While work absence represents an unpaid temporary cessation from active employment pursuant to a temporary layoff and layoff refers to a temporary spell of unemployment, unemployment captures the steady state of being out of job [10]. Bearing this in mind, we propose:

H1: Telework improves workers' labor market outcomes during catastrophic events.

${ }^{5}$ https://www.bbc.com/worklife/article/20200630-how-covid-19-ischanging-womens-lives 


\subsection{The Moderating Roles of Gender and Childcare Constraints}

Women, on average, take more childcare and household responsibilities (e.g., [11-13]). For instance, Hook [13] finds that females tend to do more time-inflexible housework when there is less public childcare. Bianchi et al. [11] suggest that females do the majority of housework and childcare, even for dual-career couples. Females are also found to have a higher need for flexibility [6] and a short commute [14]. In the US, females spend two times as much time as men on housework and childcare [12].

The lockdown has caused a surge in domestic work. For example, during the pandemic stay-at-home period, the school closure and the risks of dining at restaurants may contribute to greater family demands in childcare and housework. A recent survey finds that the surge in domestic work is accompanied by the worsened inequality of household work distribution. Ipsos's survey found that women were $4 \%$ more likely than men to say they strongly agreed that their care load increased during the pandemic. ${ }^{6}$ This result indicates the pandemic might further enlarge the gap between women's and men's domestic workload. The increasing inequality in household workload between women and men may affect the impacts of telework on labor market outcomes in two competing ways.

On the one hand, telework can help females to alleviate the work-family conflict they faced during catastrophic events, by providing flexibility in work locations and saving commuting time. As females usually have greater family responsibilities in housework and higher difficulties in balancing work and life during catastrophic events, telework is likely to empower females more than males. Bearing this in mind, we propose:

H2a: The positive effect of telework on workers' labor market outcomes during the pandemic is stronger for females than males.

H3a: The positive effect of telework on workers' labor market outcomes during the pandemic is stronger for females with childcare constraints than their counterparts as well as those without childcare constraints (regardless of gender).

On the other hand, when females are overwhelmed by the surged household workload during the pandemic, they may drop out of the labor force. In this case, they do not take the advantage of the working opportunities provided by telework during the pandemic and thus benefit less from

\footnotetext{
${ }^{6} \mathrm{https}$ ://data.unwomen.org/features/ipsos-survey-confirms-covid19-intensifying-womens-workload-home
}

telework than their male counterparts. Based on a survey from the National Academies of Sciences, Engineering, and Medicine (NASEM), over half of females reported that an increase in childcare demands during the pandemic makes it more challenging for them to deal with childcare and other family responsibilities than before. ${ }^{7}$ Besides, some recent studies on the COVID-19 pandemics also confirm that the increased need for childcare during the stay-athome period may leave a stronger negative impact on females' working hours and productivity than on those of their male counterparts. Heggeness [2] finds that school closure during the COVID-19 tends to increase the chance that females with childcare constraints are not working even if they have jobs. Similarly, Collins et al. [1] find that females significantly reduce their working hours during the pandemic, particularly those with young children, whereas there is very little change in the working hours of males with children. The above-mentioned studies all suggest that the COVID-induced childcare burden may be too heavy for females to keep their current jobs, even for those with teleworkable jobs. For instance, among scientists, whose jobs have high telework penetration rate, there is evidence suggesting that females are more likely to lose their jobs and career opportunities due to the unequal constraint by childcare. ${ }^{8}$ Given that females tend to be more constrained by the increased demand for childcare during catastrophic events, we propose:

$H 2 b$ : The positive effect of telework on workers' labor market outcomes during the pandemic is weaker for females than males.

$H 3 b$ : The positive effect of telework on workers' labor market outcomes during the pandemic is weaker for females with childcare constraints than their counterparts as well as those without childcare constraints (regardless of gender).

Based on the countervailing theoretical predictions, whether and how telework has differential effects across gender is far from clear at this stage, making it an interesting empirical question to explore. Notably, H2a and H3a suggest that telework can help to narrow the gender inequality in labor market outcomes during catastrophic events due to the stronger empowerment effect of flexibility in teleworkable jobs for females. In contrast, $\mathrm{H} 2 \mathrm{~b}$ and $\mathrm{H} 3 \mathrm{~b}$ imply that the gender inequality in labor market outcomes is widened by telework during catastrophic events when the heavier burden of childcare on females constrains females from teleworking.

\footnotetext{
${ }^{7} \mathrm{https} / / / w w w . n a t u r e . c o m / a r t i c l e s / d 41586-021-00854-\mathrm{x}$

${ }^{8}$ https://www.nature.com/articles/d41586-020-02183-x
} 


\section{Data}

To answer our research questions, we compile a rich individual-month level dataset from various sources, including individuals' demographics (e.g., age, gender, race, occupation, self-employed or not) and their labor market outcomes data from the Current Population Survey (CPS), the occupation-based teleworkability measures proposed by Del RioChanona [15], and the occupation-based demand shocks during COVID-19 pandemics [15].

Our dataset includes all the respondents aged between 15 and 64 (i.e., the working-age population) in the CPS monthly survey conducted by the Bureau of Census for the Bureau of Labor Statistics (BLS) from September 2018 to April 2021. The data set contains three measures of their labor market outcomes: Unemployed indicates whether the respondent was unemployed currently; WorkAbsent denotes whether the respondent had a job from which s/he was temporarily absent due to reasons other than layoff during the previous week; LaidOff denotes whether the respondent had a job from which he was temporarily absent due to layoff during the previous week. While being laid off and being absent from work captures a temporary cessation of work, being unemployed captures the steady state of not having a job currently.

To examine the impact of telework on workers' labor market outcomes during the pandemic, we use a continuous measure of telework treatment intensity [16]. Specifically, to construct the occupation-level telework treatment intensity, we leverage the CPS question regarding whether individuals in each occupation were teleworking in the post-COVID-19 period (since May 2020) to calculate the occupationbased telework penetration rate. By using the occupation-based telework penetration rate as the treatment intensity measure, we estimate the effect of

\section{Table 1. Variable Description}

\begin{tabular}{|c|l|l|}
\hline Variable Name & Variable Definition & Source \\
\hline Unemployed $_{i t}$ & $\begin{array}{l}\text { Whether individual } i \\
\text { is unemployed in the } \\
\text { month } t\end{array}$ & CPS \\
\hline Laidoff $_{\mathrm{it}}$ & $\begin{array}{l}\text { Whether individual } i \\
\text { is laid off during the } \\
\text { previous week in the } \\
\text { month } t\end{array}$ & CPS \\
\hline WorkAbsent $_{i t}$ & $\begin{array}{l}\text { Whether individual } i \\
\text { is absent from work }\end{array}$ & CPS \\
\hline
\end{tabular}

\footnotetext{
${ }^{9}$ See https://cps.ipums.org/cps-

action/variables/nchild\#codes_section for more detailed information about this variable.
}

change in treatment intensity (i.e., telework penetration rate) on workers' labor market outcomes by comparing the employment status of workers in jobs with high telework penetration rates and those of workers in jobs with low telework penetration rates. Furthermore, in our heterogeneous treatment analysis, considering that different demographic groups may have different telework take-up rates within an occupation, we further estimate the occupation-based telework penetration rate for each demographic group (defined by gender and childcare constraints).

To examine whether the gender inequality in labor market outcomes is widened by telework because of the heavier burden of childcare constraints on females during the pandemic, we consider the potential moderating effect of the variable ChildCare, which indicates whether the respondent had at least one child under age $5[17]^{9}$. Further, we classify respondents into four demographic groups by their genders and childcare constraints and investigate the heterogeneous effect of telework across groups.

In addition, to explicitly disentangle the effect of telework from the confounding effect of the pandemicinduced demand shock on labor market outcomes, we match the CPS respondent's occupation with the occupation-based demand shock measure during the pandemic proposed by Del Rio-Chanona [15]. Their estimates of demand shock for each occupation are based on expert estimates developed by the US Congressional Budget Office (2006), which is designed to assess the potential impact of an influenza pandemic. This expert prediction is based on the assumption that demand will decrease as people have a stronger desire to avoid infection during the pandemic.

The definitions of all variables and their statistics are summarized in Tables 1 and 2 , respectively.

\begin{tabular}{|c|l|l|}
\hline & $\begin{array}{l}\text { during the previous } \\
\text { week in month } t\end{array}$ & \\
\hline Female $_{\mathrm{i}}$ & $\begin{array}{l}\text { Whether individual } i \\
\text { is female }\end{array}$ & CPS \\
\hline Child $_{\mathrm{it}}$ & $\begin{array}{l}\text { Whether individual } i \\
\text { has at least one child } \\
\text { under age 5 in the } \\
\text { month } t\end{array}$ & CPS \\
\hline Teleworkability $_{o, g}$ & $\begin{array}{l}\text { The telework } \\
\text { penetration rates of } \\
\text { occupation } o \text { by } \\
\text { individual } i \text { 's } \\
\text { demographic group } g\end{array}$ & CPS \\
\hline
\end{tabular}




\begin{tabular}{|c|l|l|}
\hline DemandShock $_{\mathrm{o}}$ & $\begin{array}{l}\text { To what extent the } \\
\text { epidemics influence } \\
\text { consumer spending } \\
\text { regarding the } \\
\text { occupation } o .\end{array}$ & $\begin{array}{l}\text { del Rio- } \\
\text { Chanona } \\
{[9]}\end{array}$ \\
\hline SelfEmp $_{\text {it }}$ & $\begin{array}{l}\text { Whether individual } i \\
\text { is self-employed in } \\
\text { month } t\end{array}$ & CPS \\
\hline
\end{tabular}

Table 2. Summary Statistics of Variable Used

\begin{tabular}{|c|c|c|c|c|}
\hline Name & Mean & SD & Min & Max \\
\hline Unemployed & 0.05 & 0.215 & 0.00 & 0.00 \\
\hline WorkAbsent $_{i t}$ & 0.05 & 0.215 & 0.00 & 0.00 \\
\hline Laidoff $_{\text {it }}$ & 0.02 & 0.129 & 0.00 & 0.00 \\
\hline Teleworkability $_{o, g}$ & 0.22 & 0.217 & 0.00 & 0.11 \\
\hline Female $_{i}$ & 0.49 & 0.500 & 0.00 & 0.00 \\
\hline Child $_{i}$ & 0.08 & 0.274 & 0.00 & 0.00 \\
\hline DemandShock $_{\mathrm{o}}$ & -0.13 & 0.216 & -0.78 & -0.08 \\
\hline SelfEmp $_{\text {it }}$ & 0.11 & 0.318 & 0.00 & 0.00 \\
\hline
\end{tabular}

Note. We match the occupation level data with the individual-month level panel data; $i$ denotes individual, $t$ denotes month, o denotes occupation, and $g$ denotes demographic group; We only report the summary statistics for our CEM matched sample. Given our focus on gender heterogeneity, we match females with males based on age, education, state of residence, industry, occupation, marriage status, part-/full-time status, and childcare constraints.

\section{Identification Challenges and Identification Strategies}

In this study, we aim to examine the gender heterogeneous impact of telework on workers' labor

\section{Empirical Strategy}

We use the stay-at-home order as a measure of COVID-induced labor market disruption and leverage the within-worker variation in labor market outcomes before versus after the enforcement of the stay-athome order to conduct the DiD estimation to assess how telework mitigates the negative effect of the pandemic on workers' labor market outcomes. Moreover, we employ a triple-difference (DDD) design [18-20] to examine the heterogeneous effects of telework by gender during the pandemic. In the main analysis, we employ the occupation-level telework penetration rate as the treatment intensity measure. In the robustness checks, we show that results are highly consistent if we use an individuallevel treatment measure (i.e., the probability of the respondent teleworking in the post-COVID-19 period predicted based on various individual characteristics). market outcomes during the pandemic. The identification challenges facing our study are multiply folded. First, it is hard to rule out the effect of unobserved variables that are associated with both telework take-up and labor market outcomes. Second, the change in labor market outcomes during the pandemic may be confounded with the pandemicinduced demand shock across industries.

We tackle the first challenge by leveraging the exogenous shock when the COVID-19 pandemic constrains workers to work from home. Specifically, we employ the difference-in-difference (DiD) to take advantage of the exogenous surge of telework takeup during the COVID-19. Further, we estimate gender differences among workers in the lift in their labor market outcomes due to the telework using a difference-in-difference-in-differences (DDD) model. To alleviate the concern about the confounding issue related to the systematic difference of telework takeup between males and females (e.g., teleworkable females may have different skill levels than their male counterparts), we use the Coarsened Exact Matching (CEM) to match females with males based on age, education, state of residence, industry, occupation, marriage status, part-/full-time status, and childcare constraints.

Further, we explicitly control for the occupationspecific demand shocks during the pandemic to solve the third challenge. In our main analysis, we use the occupation-specific demand shock measure proposed by Del Rio-Chanona et al. [15] to control for the confounding effect of the demand shock.

The implementation of the stay-at-home order serves as our exogenous shock in our DiD design. Our DiD captures how workers' labor market outcomes vary across occupations with high or low telework penetration rates during the pandemic-induced workplace disruption.

LaborMarketOutcome $_{i t}=\beta_{1}+\beta_{2}$ Lockdown $_{t}+$ $\beta_{3}$ Telework $_{\text {og }}+\beta_{4}$ Telework $_{\text {og }} \times$ Lockdown $_{t}+$

Controls $_{\text {it }}+\alpha_{i}+\tau_{t}+\varepsilon_{i t}$

where LaborMarketOutcome ${ }_{i t}$ denote the three labor market outcome measures for individual $i$ of occupation $o$ in month $t$, namely, Unemployed ${ }_{i t}$,

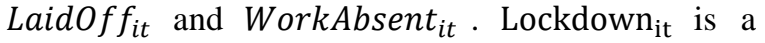
binary variable indicating whether the stay-at-home order is in effect at month $t$. Telework $\mathrm{og}_{\mathrm{g}}$ is the occupation-level telework penetration rate, capturing the telework treatment intensity for workers of demographic group $g$ in occupation $o$. Controls $s_{i t}$ include the occupation-based demand shock during the COVID-19 proposed by [15] and the time-varying effects of self-employment on individuals' labor 
market outcomes over time. $\alpha_{i}$ and $\tau_{t}$ represent the individual-level fixed effects and month fixed effects. The individual-level fixed effects control for the differences in work-life ideologies and other timeinvariant aspects (e.g., education, skill, personal traits, and health conditions), while the month fixed effects capture the common temporal shocks [21]. We cluster the error terms at the individual level to account for the potential serial correlations within individuals [18].

In our DiD specification, $\beta_{1}$ captures the impact of the stay-at-home order on workers' employment status. $\beta_{2}$ captures the impact of telework on workers' employment status. $\beta_{3}$ captures the effect of telework on workers' employment status under the stay-athome order. Based on prior discussions, we expect that $\beta_{13}$ is negative since telework helps workers to perform job-related tasks during the pandemic.

To examine the gender heterogeneous effects of telework, we estimate the following DDD model. In our DDD setup, we further disentangle the differential impacts of telework on males' and females' labor market outcomes under the COVID-19 stay-at-home order. The DDD captures how the lift in workers' labor market outcomes due to telework varies by gender. Similar to the DD model setup, we control for the individual fixed effects, month fixed effects, the demand shock during the pandemic, and the impact of self-employment during the pandemic.

LaborMarketOutcome $_{\text {it }}=\beta_{1}+\beta_{2}$ Lockdown $_{\text {it }}+$ $\beta_{3}$ Lockdown $_{\text {it }} \times$ Female $_{\mathrm{i}}+\beta_{4}$ Telework $_{\text {og }}+$ $\beta_{5}$ Telework $_{\text {og }} \times$ Female $_{\mathrm{i}}+\beta_{6}$ Telework $_{\text {og }} \times$ Lockdown $_{\text {it }}+\beta_{7}$ Telework $_{\text {og }} \times$ Lockdown $_{\text {it }} \times$ Female $_{\mathrm{i}}+$ Controls $_{\mathrm{it}}+\alpha_{\mathrm{i}}+\tau_{\mathrm{t}}+\varepsilon_{\mathrm{it}}$

To examine whether the gender heterogeneous effects of telework are moderated by the burden of childcare, with a similar DDD model, we further estimate the differential effect of telework on four demographic groups, including male workers without childcare constraints (i.e., the baseline group), male workers with childcare constraints, female workers without childcare constraints, and female workers with childcare constraints. Instead of including the Female dummy, we include (Group) ${ }_{\text {it }},{ }^{10}$ a vector of demographic group dummies (i.e., MaleChild ${ }_{i t}$, FemaleChild $_{i t}$, FemaleNoChild ${ }_{i t}$ ), and interact it with Lockdown it $_{\text {and Telework }}$. LaborMarketOutcome $_{i t}=\beta_{1}+\beta_{2}$ Lockdown $_{i t}+$ $\beta_{3}$ Lockdown $_{\text {it }} \times\left(\right.$ Group $_{\text {it }}+\beta_{4}$ Telework $_{\text {og }}+$ $\beta_{5}$ Telework $_{\text {og }} \times\left(\right.$ Group $_{\text {it }}+\beta_{6}$ Telework $_{\text {og }} \times$ Lockdown $_{\text {it }}+\beta_{7}$ Telework $_{\mathrm{og}} \times$ Lockdown $_{i t} \times$ $\left(\right.$ Group $_{i t}+$ Controls $_{\mathrm{it}}+\alpha_{\mathrm{i}}+\tau_{\mathrm{t}}+\varepsilon_{\mathrm{it}}$

\section{Empirical Results}

\subsection{Main Effect of Teleworkability}

We first examine the effect of telework on workers' labor market outcomes with the DiD model. Workers' labor market outcomes include unemployment, work absence, and lay-off. As Table 3 shows, workers in occupations with high telework penetration rates are less likely to be unemployed, absent from work, or laid off during the COVID-19 pandemic. Specifically, 1 S.D. increase in telework penetration rate by workers (i.e., 0.217) can offset the increase in the unemployment rate due to the pandemic by $20 \%(0.217 *(-0.0391) / 0.0425=-20 \%)$, that in work absence by $28 \% \quad(0.217 *(-$ $0.0626) / 0.0490=-28 \%$ ), and that in layoff by $26 \%$ $(0.217 *(-0.0461) / 0.0383=-26 \%)$. These results provide us remarkable evidence that telework significantly reduces workers' unemployment, work absence, and layoff. This suggests that telework helps improve workers' labor market outcomes during catastrophic events (H1 is supported).

Table 3. Impact of the Telework on Labor Market Outcomes During the Pandemic

\begin{tabular}{|c|c|c|c|}
\hline & $(1)$ & (2) & (3) \\
\hline Dep. Var. & Unemployed $_{i t}$ & WorkAbsent $_{i t}$ & Laidoff $_{i t}$ \\
\hline Lockdown $_{i t}$ & $\begin{array}{c}0.0425 * * * \\
(0.00192)\end{array}$ & $\begin{array}{c}0.0490 * * * \\
(0.00267)\end{array}$ & $\begin{array}{c}0.0383 * * * \\
(0.00150)\end{array}$ \\
\hline Telework & $\begin{array}{c}0.0169 * * * \\
(0.00645)\end{array}$ & $\begin{array}{c}0.0443 * * * \\
(0.00684)\end{array}$ & $\begin{array}{c}0.0290 * * * \\
(0.00467)\end{array}$ \\
\hline Telework $_{\text {og }} \times$ Lockdown $_{i t}$ & $\begin{array}{c}-0.0391 * * * \\
(0.00444)\end{array}$ & $\begin{array}{c}-0.0626 * * * \\
(0.00591)\end{array}$ & $\begin{array}{c}-0.0461 * * * \\
(0.00340)\end{array}$ \\
\hline
\end{tabular}

\footnotetext{
${ }^{10}$ The measure of childcare constraints is time-variant since some respondents had their kids born within the survey window.
} 


\begin{tabular}{cccc}
\hline Observations & 626,573 & 626,573 & 626,573 \\
R-squared & 0.646 & 0.427 & 0.490 \\
Individual FE & Yes & Yes & Yes \\
Month FE & Yes & Yes & Yes \\
Demand Shock During Pandemic & Yes & Yes & Yes \\
Self-Employment During Pandemic & Yes & Yes & Yes \\
\hline \multicolumn{2}{l}{ Robust standard errors are clustered by individuals; $* * *$} & $p<0.01, * * p<0.05, * p<0.1$
\end{tabular}

\subsection{Gender Heterogeneity}

We then investigate whether the effect of telework on workers' labor market outcomes varies by gender following our DDD specification. As Table 4 shows, the positive effect of telework on workers' labor market outcomes is stronger for females than their male counterparts. Specifically, the effect of telework for females is 3.4 times stronger than that for males in reducing unemployment $\left(-0.0615^{11}\right.$ vs. $0.018)$, is 2.3 times stronger in reducing work absence $\left(-0.0887^{12}\right.$ vs. -0.0387$)$, and is 1.8 times stronger in reducing layoff $\left(-0.0598^{13}\right.$ vs. -0.0339$)$. These results provide us strong evidence that telework helps females more than their male counterparts ( $\mathrm{H} 2 \mathrm{a}$ is supported and $\mathrm{H} 2 \mathrm{~b}$ is not supported).

Table 4. Gender Heterogeneous Impact of Telework on Labor Market Outcomes During the Pandemic

\begin{tabular}{cccc}
\hline & $(1)$ & $(2)$ & $(3)$ \\
Dep. Var. & Unemployed $_{i t}$ & WorkAbsent $_{i t}$ & Laidoff $_{i t}$ \\
\hline Lockdown $_{i t}$ & $0.0351^{* * *}$ & $0.0393 * * *$ & $0.0326^{* * *}$ \\
& $(0.00297)$ & $(0.00402)$ & $(0.00232)$ \\
Telework $_{\text {og }}$ & 0.00790 & $0.0349 * * *$ & $0.0274^{* * *}$ \\
& $(0.0108)$ & $(0.0111)$ & $(0.00811)$ \\
Telework $_{\text {og }} \times$ Lockdown $_{i t}$ & $-0.0180^{* *}$ & $-0.0387^{* * *}$ & $-0.0339^{* * *}$ \\
& $(0.00725)$ & $(0.00916)$ & $(0.00557)$ \\
Female $_{i} \times$ Lockdown $_{i t}$ & $0.0156^{* * *}$ & $0.0204^{* * *}$ & $0.0119^{* * *}$ \\
& $(0.00346)$ & $(0.00427)$ & $(0.00276)$ \\
Female $_{i} \times$ Telework $_{\text {og }}$ & 0.0187 & 0.0199 & 0.00395 \\
& $(0.0129)$ & $(0.0137)$ & $(0.00941)$ \\
Female $_{i} \times$ Telework $_{\text {og }} \times$ Lockdown $_{i t}$ & $-0.0435^{* * *}$ & $-0.0500^{* * *}$ & $-0.0259^{* * *}$ \\
& $(0.00868)$ & $(0.0107)$ & $(0.00668)$ \\
\hline Observations & 626,573 & 626,573 & 626,573 \\
R-squared & 0.646 & 0.427 & 0.490 \\
Individual FE & Yes & Yes & Yes \\
Month FE & Yes & Yes & Yes \\
Yes & Yes & Yes \\
Semand Shock During Pandemic & Yes & Yes & Yes \\
\hline Robust standard errors are clustered by individuals; *** $p<0.01, * * p<0.05, * p<0.1$
\end{tabular}

To further examine whether childcare constraints can amplify or weaken gender heterogeneous effects of telework, we run our DDD models by including three demographic group dummies by gender and childcare constraints (i.e., MaleChild, FemaleChild, FemaleNoChild) and using the MaleNoChild group as the baseline. Table 5 shows that the positive effect of telework on labor market outcomes is strongest for females when they have childcare constraints. Specifically, the effect of telework in reducing unemployment for females with childcare constraints, is 7.1 times stronger than that for males without childcare constraints, is 1.5 times stronger than that for males with child constraints, and is 1.5 times stronger than that for females without childcare constraints. The effect of telework in reducing work absence for females with childcare constraints, is 2.4 times stronger than that for males without childcare constraints, is 3.0 times stronger than that for males with child constraints, and is 1.1 times stronger than that for females without childcare constraints. The effect of telework in reducing layoff for females with

${ }^{13}-0.0339+(-0.0259)$ 
childcare constraints, is 2.2 times stronger than that for males without childcare constraints, is 1.8 times stronger than that for males with child constraints, and is 1.3 times stronger than that for females without childcare constraints. All these differences are statistically significant. These consistent findings provide strong support for our $\mathrm{H} 3 \mathrm{a}$ ( $\mathrm{H} 3 \mathrm{~b}$ is not supported).

Table 5. Gender Heterogeneous Impact of Telework on Labor Market Outcomes During the Pandemic by Childcare Constraint

\begin{tabular}{|c|c|c|c|}
\hline \multirow[b]{2}{*}{ Baseline Group } & (1) & (2) & (3) \\
\hline & \multicolumn{3}{|c|}{ Male_Nochild $_{i t}$} \\
\hline Dep. Var. & Unemployed $_{i t}$ & WorkAbsent $_{i t}$ & Laidoff $_{i t}$ \\
\hline \multirow[t]{2}{*}{ Lockdown $_{i t}$} & $0.0331 * * *$ & $0.0397 * * *$ & $0.0323 * * *$ \\
\hline & $(0.00311)$ & $(0.00426)$ & $(0.00242)$ \\
\hline \multirow{2}{*}{ Telework $_{o g}$} & 0.00666 & $0.0286 * *$ & $0.0267 * * *$ \\
\hline & $(0.0115)$ & $(0.0119)$ & $(0.00871)$ \\
\hline \multirow[t]{2}{*}{ Telework $_{\text {og }} \times$ Lockdown $_{i t}$} & -0.0126 & $-0.0396 * * *$ & $-0.0331 * * *$ \\
\hline & $(0.00805)$ & $(0.0101)$ & $(0.00618)$ \\
\hline \multirow[t]{2}{*}{ Female_Child $_{i t}$} & 0.000715 & $0.0727 * * *$ & 0.00150 \\
\hline & $(0.00620)$ & $(0.00881)$ & $(0.00404)$ \\
\hline \multirow[t]{2}{*}{ Male_Child $_{i t}$} & 0.00413 & $0.0289 * * *$ & 0.00619 \\
\hline & $(0.00666)$ & $(0.0100)$ & $(0.00540)$ \\
\hline \multirow{2}{*}{ Female_Child $_{i t} \times$ Lockdown $_{i t}$} & $0.0269 * * *$ & $0.0193 *$ & $0.0176 * * *$ \\
\hline & $(0.00700)$ & $(0.00996)$ & $(0.00567)$ \\
\hline \multirow{2}{*}{ Female_Nochild $_{i t} \times$ Lockdown $_{i t}$} & $0.0165 * * *$ & $0.0205 * * *$ & $0.0117 * * *$ \\
\hline & $(0.00363)$ & $(0.00451)$ & $(0.00289)$ \\
\hline \multirow[t]{2}{*}{ Male_Child $_{i t} \times$ Lockdown $_{i t}$} & $0.0218 * *$ & -0.00247 & 0.00444 \\
\hline & (0.00987) & $(0.0112)$ & $(0.00837)$ \\
\hline \multirow[t]{2}{*}{ Female_Child $_{i t} \times$ Telework $k_{\text {og }}$} & 0.0113 & 0.0313 & 0.00288 \\
\hline & $(0.0181)$ & $(0.0253)$ & $(0.0125)$ \\
\hline \multirow[t]{2}{*}{ Female_Nochild $_{i t} \times$ Telework $k_{o g}$} & 0.0210 & $0.0243^{*}$ & 0.00488 \\
\hline & $(0.0138)$ & $(0.0144)$ & $(0.0100)$ \\
\hline \multirow{2}{*}{ Male_Child $_{i t} \times$ Telework ${ }_{\text {og }}$} & 0.00563 & 0.0228 & 0.00114 \\
\hline & $(0.0140)$ & $(0.0196)$ & $(0.0102)$ \\
\hline \multirow[t]{2}{*}{ Female_Child $_{i t} \times$ Telework ${ }_{o g} \times$ Lockdown $_{i t}$} & $-0.0773 * * *$ & $-0.0572 * *$ & $-0.0406 * * *$ \\
\hline & $(0.0158)$ & $(0.0255)$ & $(0.0125)$ \\
\hline \multirow[t]{2}{*}{ 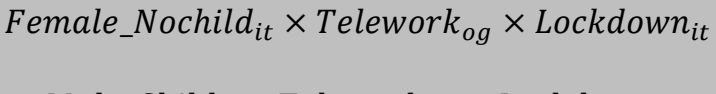 } & $-0.0456 * * *$ & $-0.0484 * * *$ & $-0.0252 * * *$ \\
\hline & $(0.00951)$ & $(0.0115)$ & $(0.00731)$ \\
\hline \multirow[t]{2}{*}{ Male_Child $_{i t} \times$ Telework $_{\text {og }} \times$ Lockdown $_{i t}$} & $-0.0476 * * *$ & 0.00734 & -0.00796 \\
\hline & $(0.0182)$ & $(0.0219)$ & $(0.0147)$ \\
\hline Observations & 626,573 & 626,573 & 626,573 \\
\hline R-squared & 0.646 & 0.427 & 0.490 \\
\hline Individual FE & Yes & Yes & Yes \\
\hline Month FE & Yes & Yes & Yes \\
\hline Demand Shock During Pandemic & Yes & Yes & Yes \\
\hline Self-Employment During Pandemic & Yes & Yes & Yes \\
\hline
\end{tabular}

\section{Discussion and Conclusion}

Recent studies suggest that the catastrophic advent of COVID-19 has stronger negative effects on females than males, and thus further widens the gender employment gap (e.g., [1-2,22]). We add to the emerging literature on the economic consequences of telework for gender inequality by investigating the 
differential effects of telework on workers' labor market outcomes by gender and its effect on the gender employment gap. Leveraging the implementation of the stay-at-home order, we first quantify the positive effect of telework, i.e., 1 S.D. increase in telework penetration rate can offset the increase in the unemployment rate due to the pandemic by $20 \%$, that in work absence by $28 \%$, and that in layoff by $26 \%$. We further show that the positive effect of telework on workers' labor market outcomes is stronger for females. Moreover, given that females with childcare constraints tend to have a higher need for flexibility, they benefit more from telework than their male counterparts as well as those without childcare constraints.

Our study has several key contributions. First, our study contributes to the growing literature on the economic consequences of telework on workers' labor market outcomes during the COVID-19 pandemic. Prior literature on telework suggests that telework can improve workers' productivity by reducing sick days and improving response time [9]. Since the beginning of COVID-19, recent working papers turn to focus on the measurement of teleworkability (e.g., [3,15,23]), demographic distributions in teleworkable vs. nonteleworkable jobs (e.g., [24-25]), and the actual takeup rate of telework (e.g., [26-27]). To extend this stream of literature, we leverage the implementation of the stay-at-home order to provide a rigorous quantification of the positive effect of telework on workers' labor market outcomes and highlight the heterogeneous effects of telework on workers' labor market outcomes by gender.

Second, our study contributes to the growing literature on gender inequality by highlighting the critical importance of telework during catastrophic events. An interesting tension arises when one considers how telework might influence gender inequality in labor market outcomes during the pandemic. On the one hand, females need flexibility more than males to alleviate the work-family conflict during the pandemic and telework may help females more than their male counterparts. On the other hand, when females are overwhelmed by the surged household workload and cannot fully take advantage of the telework opportunities, they may benefit less from telework. Exploiting a DDD specification to compare the lift in workers' labor market outcomes due to telework, we find consistent evidence that the positive effect of the increased flexibility dominates the negative effect of increased constraints, and thus telework helps to narrow the gender employment gap during the pandemic.

Our study has important implications for public policy and workers. Our study indicates that firms should consider the heterogeneity in the need for flexibility and telework. Firms are advised to provide workers the telework option and more guidance on how to telework efficiently. Additionally, since telework is more important to females with childcare constraints, they should acquire more telework soft skills and improve home technologies (e.g., Internet, computers) to maximize their telework productivity. Further, our additional analysis shows that females can benefit more from telework in states with lower gender inequity in time spent on household workload (detailed results are omitted due to limited space). Therefore, the more gender equality in household responsibility and the more support from other family members can also help to amplify the positive effect of telework on females.

Our work is not without limitations. The study only considers the average effect of telework penetration on workers' labor market outcomes across occupations. It would be interesting to see the dynamics of workers' employment status change (e.g., the transition from unemployed to employed and vice versa) by supplementing the employment data with both opening data and job turnover data.

\section{References}

[1] Collins, C., Landivar, L. C., Ruppanner, L., \& Scarborough, W. J. (2021). COVID-19 and the gender gap in work hours. Gender, Work \& Organization, 28, 101-112.

[2] Heggeness, M. L. 2020. "Estimating the Immediate Impact of the COVID-19 Shock on Parental Attachment to the Labor Market and the Double Bind of Mothers," Review of Economics of the Household, Springer, pp. 1-26.

[3] Dingel, J. I., and Neiman, B. 2020. "How Many Jobs Can Be Done at Home?," NBER.

[4] Crossan, G., and Burton, P. F. 1993. "Teleworking Stereotypes: A Case Study,” Journal of Information Science (19:5), Sage Publications Sage UK: London, England, pp. 349-362

[5] Duxbury, L., and Neufeld, D. 1999. “An Empirical Evaluation of the Impacts of Telecommuting on IntraOrganizational Communication," Journal of Engineering and Technology Management (16:1), Elsevier, pp. 1-28.

[6] Mas, A., and Pallais, A. 2017. "Valuing Alternative Work Arrangements," American Economic Review (107:12), pp. 3722-3759. (https://doi.org/10.1257/aer.20161500).

[7] Choudhury, P., Foroughi, C., \& Larson, B. (2021). Work-from-anywhere: The productivity effects of geographic flexibility. Strategic Management Journal, 42(4), 655-683.

[8] Lyttelton, T., Zang, E., and Musick, K. 2020. “Gender Differences in Telecommuting and Implications for 
Inequality at Home and Work," Available at SSRN 3645561.

[9] Bloom, N., Liang, J., Roberts, J., and Ying, Z. J. 2015. "Does Working from Home Work? Evidence from a Chinese Experiment," The Quarterly Journal of Economics (130:1), MIT Press, pp. 165-218.

[10] Polivka, A. E., \& Miller, S. M. 2007. The CPS after the Redesign: Refocusing the Economic Lens (pp. 249-290). University of Chicago Press.

[11] Bianchi, S. M., Milkie, M. A., Sayer, L. C., and Robinson, J. P. 2000. "Is Anyone Doing the Housework? Trends in the Gender Division of Household Labor," Social Forces (79:1), Oxford University Press, pp. 191-228.

[12] Gelbach, J. B. 2002. "Public Schooling for Young Children and Maternal Labor Supply," American Economic Review (92:1), pp. 307-322.

[13] Hook, J. L. 2010. "Gender Inequality in the Welfare State: Sex Segregation in Housework, 1965-2003," American Journal of Sociology (115:5), The University of Chicago Press, pp. 1480-1523.

[14] Le Barbanchon, T., Rathelot, R., and Roulet, A. 2020. Gender Differences in Job Search: Trading off Commute against Wage, CEPR Discussion Paper No. DP15181.

[15] Del Rio-Chanona, R. M., Mealy, P., Pichler, A., Lafond, F., \& Farmer, J. D. (2020). Supply and demand shocks in the COVID-19 pandemic: An industry and occupation perspective. Oxford Review of Economic Policy, 36(Supplement_1), S94-S137.

[16] Angrist, J., \& Imbens, G. (1995). Identification and estimation of local average treatment effects.

[17] Hashikawa, A. N., Sells, J. M., DeJonge, P. M., Alkon, A., Martin, E. T., \& Shope, T. R. (2020). Child Care in the Time of Coronavirus Disease-19: A Period of Challenge and Opportunity. The Journal of Pediatrics, 225, 239-245.

[18] Bertrand, M., Duflo, E., and Mullainathan, S. 2004. "How Much Should We Trust Differences-inDifferences Estimates?," The Quarterly Journal of Economics (119:1), pp. 249-275.

[19] Greenwood, B. N., and Wattal, S. 2017. "Show Me the Way to Go Home: An Empirical Investigation of Ride-Sharing and Alcohol Related Motor Vehicle Fatalities.," MIS Q. (41:1), pp. 163-187.

[20] He, S., Peng, J., Li, J., and Xu, L. 2020. "Impact of Platform Owner's Entry on Third-Party Stores," Information Systems Research, Forthcoming.

[21] Sabzehzar, A., Hong, Y., \& Raghu, T. S. (2021). People don't change, their priorities do: Evidence of value homophily for disaster relief. ICIS 2020 Proceedings.

[22] Cui, R., Ding, H., \& Zhu, F. (2020). Gender inequality in research productivity during the COVID-19 pandemic. arXiv preprint arXiv:2006.10194.

[23] Mongey, S., Pilossoph, L., and Weinberg, A. 2020. "Which Workers Bear the Burden of Social Distancing Policies?," National Bureau of Economic Research.

[24] Adams-Prassl, A., Boneva, T., Golin, M., and Rauh, C. 2020. Work Tasks That Can Be Done From Home:
Evidence on Variation Within \& Across Occupations and Industries, CEPR Discussion Paper No. DP14901.

[25] Béland, L. P., Brodeur, A., \& Wright, T. (2020). The short-term economic consequences of Covid-19: exposure to disease, remote work and government response.

[26] Bick, A., Blandin, A., and Mertens, K. 2020. Work from Home after the COVID-19 Outbreak, CEPR Discussion Paper No. DP15000.

[27] Brynjolfsson, E., Horton, J. J., Ozimek, A., Rock, D., Sharma, G., and TuYe, H.-Y. 2020. "COVID-19 and Remote Work: An Early Look at US Data," National Bureau of Economic Research (NBER). 